\title{
Peningkatan Kemampuan Operasi Hitung Siswa Melalui Bimbingan Belajar dan Lomba Cerdas Cermat Di Desa Simandraolo
}

\author{
Rohpinus Sarumaha ${ }^{1}$, Yohana Theresia Venty Fau ${ }^{2}$ \\ ${ }^{1}$ Program Studi Pendidikan Matematika, STKIP Nias Selatan, Nias Selatan, Indonesia \\ ${ }^{2}$ Program Studi Pendidikan Biologi, STKIP Nias Selatan, Nias Selatan, Indonesia \\ Email: ${ }^{1}$ roisarma@gmail.com, ${ }^{2}$ yohannatheresia2016@gmail.com
}

\begin{abstract}
The COVID-19 outbreak had a major impact on the world of education, so the government decided to conduct online learning as an effort to break the chain of the spread of Covid-19. Online learning involves elements of technology and experiences obstacles when learning, including the network is not smooth, lack of knowledge, to the lack of student participation when learning online. This has an impact on student learning outcomes. Elementary schools in Simandraolo Village conduct online learning, especially mathematics, most students have difficulty in performing arithmetic operations such as addition, subtraction, multiplication and division of integers and fractions. Based on these problems, it is necessary to conduct tutoring activities for students so that students can be helped in overcoming the problems they experience and carry out Smart Contest activities so that students are more motivated in learning. This activity is divided into several stages as follows: preliminary stage, action stage, final stage. Based on the tutoring activities and the quiz competition, it can be concluded that students' difficulties can be overcome by conducting tutoring and quiz competitions. Based on this service activity, it is recommended that students be more active in learning. Doing exercises that are continuous and repeated so that the concepts of integer and fractional operations can be permanently embedded in the mind.
\end{abstract}

Keywords: Integers and Fractions, Tutoring, Quiz Contest, Counting Operations

\begin{abstract}
Abstrak
Wabah COVID-19 memberikan dampak besar terhadap dunia pendidikan sehingga pemerintah memutuskan melakukan pembelajaran secara daring sebagai upaya memutus mata rantai penyebaran Covid-19. Pembelajaran secara daring melibatkan unsur teknologi dan mengalami hambatan disaat pembelajaran antara lain jaingan tidak lancar, kurangnya pengetahuan, hingga kurangnya partisipasi siswa saat pembelajaran daring. Hal tersebut memberikan dampak terhadap hasil belajar siswa. Sekolah dasar di Desa Simandraolo melakukan pembelajaran daring khususnya mata pelajaran matematika, sebagian besar siswa mengalami kesulitan dalam melakukan operasi hitung seperti penjumlahan, pengurangan, perkalian serta pembagian bilangan bulat dan pecahan. Berdasarkan permasalahan tersebut, perlu dilakukan kegiatan bimbingan belajar kepada siswa sehingga siswa dapat terbantu dalam mengatasi permasalahan yang dialami serta melaksanakan kegiatan LCC agar siswa lebih terpacu dalam belajar. Kegiatan ini dibagi menjadi beberapa tahapan sebagai berikut: Tahap pendahuluan, tahap tindakan, tahap akhir. Berdasarkan kegiatan bimbingan belajar dan LCC yang dilakukan dapat disimpulkan bahwa kesulitan siswa dapat teratasi dengan melakukan bimbingan belajar dan LCC. Berdasarkan kegiatan pengabdian ini disarankan agar siswa lebih giat untuk belajar. Melakukan latihan yang sifatnya terus menerus dan berulang ulang sehingga konsep operasi bilangan bulat dan pecahan dapat tertanam dalam benak secara permanen.
\end{abstract}

Kata Kunci: Bilangan Bulat dan Pecahan, Bimbingan Belajar, Lomba Cerdas Cermat, Operasi Hitung

\section{A. PENDAHULUAN}

Wabah COVID-19 (Simbolon \& Harahap, 2021) memberikan dampak besar terhadap dunia pendidikan. Pemerintah Indonesia memutuskan untuk melakukan pembelajaran secara daring atau pembelajaran jarak jauh sebagai upaya memutus mata rantai penyebaran Covid-19 yang mengalami peningkatan akhir-akhir ini di Tahun 2021. Pembelajaran secara daring melibatkan unsur 
teknologi sebagai sarana dan jaringan internet (Nugraha et al., 2020) sebagai sistem. (Fitriyani et al., 2020) menegaskan bahwa tidak semua peserta didik akan sukses dalam pembelajaran online, hal itu disebabkan karena perbedaan faktor lingkungan belajar dan karakteristik peserta didik. Hambatan yang muncul saat pembelajaran dilaksanakan secara daring antara lain akses sinyal yang tidak lancar, kurangnya pengetahuan dalam pengoperasian aplikasi belajar daring, hingga kurangnya partisipasi siswa saat pembelajaran daring berlangsung (Sari et al., 2021). Hal tersebut tentunya akan memberikan dampak terhadap hasil belajar siswa.

Sekolah Dasar yang berada di Desa Simandraolo Kecamatan O'Ou Kabupaten Nias selatan juga ikut serta mengadakan pembelajaran secara daring. Pembelajaran yang diterapkan pada pembelajaran secara daring salah satunya yakni pembelajaran matematika. Matematika adalah ilmu tentang bilangan, hubungan antara bilangan, dan prosedur operasional yang digunakan dalam menyelesaikan masalah mengenai bilangan yang meliputi operasi hitung (Andriyani \& Pranata, 2021). Berhitung adalah cabang matematika yang berkenaan dengan sifat hubungan-hubungan bilangan nyata dengan perhitungan-perhitungan mereka menyangkut penjumlahan, pengurangan, perkalian, dan pembagian. Sekalipun sebagai cabang, berhitung telah menjelujuri seluruh tubuh matematika.

Hasil pemantauan kami terhadap permasalahan yang dihadapi guru Sekolah Dasar di Desa Simandraolo saat pembelajaran daring khususnya mata pelajaran matematika yaitu sebagian besar siswa mengalami kesulitan dalam melakukan operasi hitung seperti penjumlahan, pengurangan, perkalian serta pembagian (Andriyani \& Pranata, 2021). Kesulitan tersebut ditandai dengan hasil belajar matematika siswa yang rendah, tidak menyelesaikan tugas dengan tepat waktu (Chairulhaq et al., 2021) karena asik bermain game, cenderung menyontek hasil pekerjaan teman, dan lain sebaginya. Hal ini dikarenakan sistem pembelajaran secara daring yang tidak efektif sehingga berakibat pada hasil belajar siswa (Supriatna et al., 2017). Ketidakefektifan ini terletak pada pemahaman siswa dalam menggunakan platform pembelajaran daring, minimnya akses internet untuk mengunduh materi-materi yang diberikan guru, serta yang paling utama adalah kemampuan orang tua yang rendah dalam menyediakan segala kebutuhan anak untuk menunjang pembelajaran daring.

Keterlibatan orang tua merupakan faktor penting pada proses belajar dan pencapaian belajar siswa (Gularso et al., 2021). Rata-rata orang tua yang berada di Desa Simandraolo bekerja sebagai petani dan buruh. Hal ini menunjukkan bahwa orang tua lebih banyak menghabiskan waktu dari pagi hingga sore untuk bekerja sehingga tidak memungkinkan untuk membimbing anak-anak ketika pembelajaran daring berlangsung. Selain itu, orang tua juga mengalami kesulitan dalam mendampingi belajar matematika pada anaknya dikarenakan orangtua masih memiliki wawasan pemahaman matematika yang terbatas.

Berdasarkan hal tersebut maka dipandang perlu adanya bimbingan belajar (Ahmad et al., 2019; Rosidah \& Faizal, 2020) kepada anak sekolah dasar yang ada di Desa Simandraolo. Bimbingan belajar adalah proses bantuan yang diberikan kepada siswa agar dapat mengatasi masalah-masalah yang dihadapinya dalam belajar sehingga siswa dapat mencapai hasil belajar yang optimal (Ilyas et al., 2020). Masalah-masalah yang dimaksud adalah kesulitan (Jera et al., 2020) siswa dalam memahami dan melakukan operasi penjumlahan, pengurangan, perkalian dan pembagian pada bilangan bulat serta pecahan. Layanan bimbingan belajar merupakan bagian layanan bimbingan dan konseling yang bertujuan untuk membantu peserta didik mengembangkan diri, sikap dan kebiasaan belajar (Manik, 2020; Sujiwo, 2017). Senada dengan (Zulyanti, 2016) yang menyatakan bahwa bimbingan belajar adalah bimbingan yang diberikan oleh tenaga ahli untuk membantu individu dalam menghadapi dan memecahkan masalah-masalah akademik.

Disamping melaksanakan bimbingan belajar, dilakukan kegiatan lomba cerdas cermat (LCC) agar siswa semakin semangat untuk belajar dan menumbuhkan rasa percaya diri (Santoso et al., 2021; Wondo \& Meke, 2021) siswa pada pelajaran matematika. Disekolah lomba cerdas cermat ini termasuk pada kategori ekstrakurikuler yang mana bertujuan untuk menumbuhkan karakter seperti menumbuhkan sikap sosial, percaya diri, bertanggung jawab, disiplin, mandiri, dapat dan bekerjasama dengan orang lain (Dewi et al., 2021). Berdasarkan permasalahan tersebut di atas, dirasa perlu dilakukan kegiatan bimbingan belajar kepada siswa, sehingga siswa dapat terbantu dalam mengatasi permasalahan yang dialami pada saat pembelajaran matematika berlangsung serta melaksanakan kegiatan lomba cerdas cermat (Santoso et al., 2021) agar siswa lebih terpacu dalam belajar. Lomba ini akan dengan mudah menggali potensi dan memotivasi siswa minatnya kurang terhadap mata pelajaran matematika (Saragih et al., 2020). Kegiatan pengabdian ini diharapkan memberikan manfaat kepada siswa untuk dapat memahami materi operasi hitung, orang tua dan guru semakin memahami betapa pentingnya pemberian bimbingan kepada siswa pada situasi dan kondisi seperti saat ini.

\section{B. PELAKSANAAN DAN METODE}

Khalayak sasaran pengabdian ini adalah siswa SD di Desa Simadraolo yang berjumlah 58 orang. 
peserta berasal dari tingkat kelas yang berbeda-beda yaitu kelas $4 \mathrm{SD}$ sampai dengan kelas 6 SD. Kegiatan bimbingan yang dilakukan dilaksanakan pada bulan Agustus 2021 selama 12 kali pertemuan sesuai jadwal yang telah ditetapkan. Agar pengabdian dapat berjalan dengan lancar maka kegiatan ini dibagi menjadi beberapa tahapan sebagai berikut: Tahap pendahuluan, tahap tindakan, tahap akhir.

Tahap pendahuluan, tahap ini dilakukan untuk menganalisis situasi dan kondisi awal siswa SD di desa Simadraolo. Kegiatan analisis ini dilakukan dengan cara mengobservasi anak-anak yang masih SD di desa Simadraolo dan mewawancarai secara langsung terkait cara belajar dan kesulitan mereka pada pembelajaran matematika selama pandemi covid-19. Hasil tahap pendahuluan tersebut menjadi alasan utama dalam melakukan tindakan pengabdian.
Tahap tindakan, pada tahap ini dilakukan beberapa kegiatan yaitu melakukan bimbingan belajar dan melaksanakan kegiatan lomba cerdas cermat (LCC). Kegiatan bimbingan belajar dilakukan melalui metode ceramah dan diskusi dengan materi operasi penjumlahan, pengurangan, perkalian, dan pembagian. Sedangkan kegiatan LCC dilakukan pada akhir kegiatan untuk merefleksi kegiatan bimbingan belajar sekaligus menumbuhkan rasa percaya diri.

Tahap akhir, pada tahap ini dilakukan kegiatan evaluasi keberlanjutan kegiatan bimbingan belajar, sekaligus membentuk gugus pelaksana bimbingan belajar yang langsung dibawahi oleh kepala desa. Untuk lebih jelas seluruh tahapan kegiatan pengabdian ini dapat lihat pada gambar 1 di bawah ini.
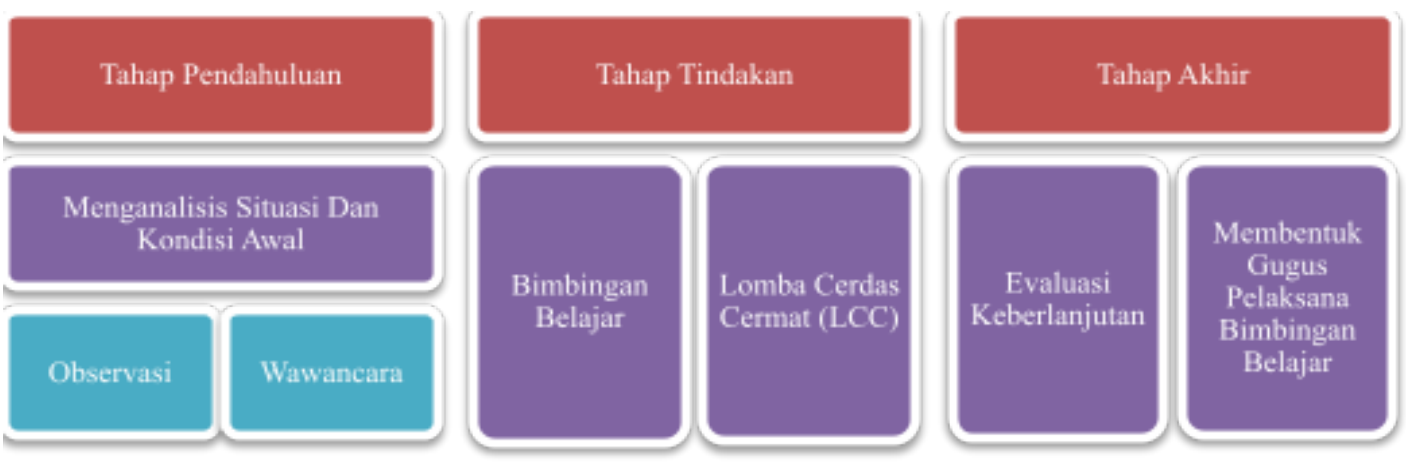

Gambar 1. Tahapan Kegiatan Bimbingan Belajar dan Lomba Cerdas Cermat

\section{HASIL DAN PEMBAHASAN}

Berdasarkan pengabdian yang dilaksanakan pada bulan Agustus 2021 selama 12 kali pertemuan diperoleh bahwa siswa masih terkendala dalam menyelesaikan permasalahan operasi bilangan. Hal ini dapat di buktikan dengan hasil pemberian tes awal pada materi operasi bilangan dengan nilai rata-rata 45 . Hal ini membuktikan bahwa siswa sangat kesulitan dalam menyelesaikan operasi bilangan secara khusus pada operasi pekalian multi digit dan pembagian, operasi campuran serta operasi bilangan pada bilangan pecahan. Dari permasalahan tersebut, dilakukanlah bimbingan belajar kepada siswa untuk meningkatkan kemampuan siswa pada operasi bilangan secara khusus pada materi bilangan bulat dan pecahan. Sehingga siswa mampu dalam menyelesaikan kasus operasi bilangan bulat dan pecahan. Hal tersebut dapat dilihat pada gambar 2 di bawah ini.

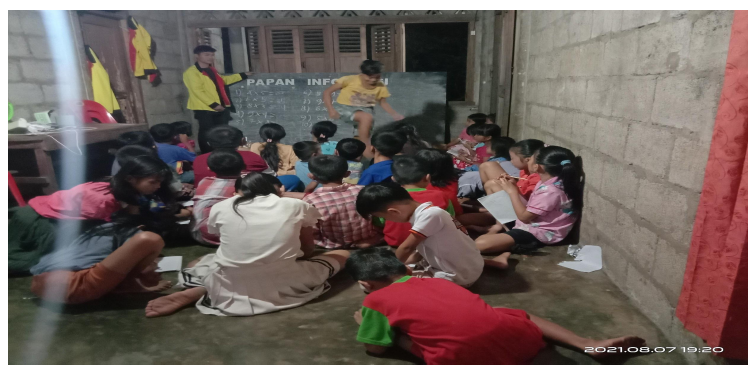

Gambar 2. Kegiatan Bimbingan Belajar Matematika

Selama kegiatan bimbingan belajar siswa termotivasi (Akbar \& Cuyatno, 2016) untuk belajar. Dimana siswa serius dalam menyelesaikan tugas yang diberikan, berperan aktif dalam proses pembelajaran, serta adanya rasa ingin tahu yang mendalam.

Selain kegiatan bimbingan belajar tersebut, juga dilakukan kegiatan pendukung berupa lomba cerdas cermat (LCC). Kegiatan ini dilakukan pada tanggal 30 Agustus 2021 dan dihadiri langsung oleh kepala desa juga aparat desa lainnya serta 
beberapa orang tua siswa. Kegiatan ini sangat disambut baik oleh masyarakat terlebih-lebih anak-anak yang menjadi peserta lomba. Kegiatan ini dapat dilihat pada gambar 3 di bawah ini. bermain-main dengan teman-teman mereka disaat jadwal pembelajaran. Siswa tergantung kepada teman-teman mereka yang memiliki handphone. Wawancara dilakukan untuk mengetahui pendapat siswa terkait pembelajaran yang dilakukan. Informasi yang diperoleh adalah siswa tidak paham pa maksud dari materi yang disampaikan oleh uru, tidak tau cara menggunakan aplikasi embelajaran karena tidak ada yang mengajari, ringan tidak ada. Disamping itu siswa cenderung dak menyelesaikan PR karena tidak paham bnsep.

ada tahap tindakan kegiatan yang dilakukan lalah melakukan kegiatan bimbingan belajar dan romba cerdas cermat. Sebelum kegiatan bimbingan belajar dilakukan, terlebih dahulu melakukan tes awal, menyusun jadwal bimbingan belajar dan melakukan tes akhir. Tes awal diberikan kepada siswa untuk mengetahui kemampuan awal siswa, hal ini dilakukan agar bimbingan belajar lebih diutamakan pada materi yang dirasa sangat sulit bagi siswa. Penyusunan jadwal bimbingan juga penting dirumuskan agar pelaksanaan bimbingan dapat berjalan dengan baik dan sistematis. Pelaksanaan bimbingan ini dilaksanakan selama 12 kali atau 3 kali dalam seminggu. Untuk lebih jelasnya jadwal yang dilakukan dapat dilihat pada tabel 1 di bawah ini. (Atsisari et al. 2021) dan 1 Whatsapp (Arsisari et al., 2021) dan Messenger, hasil yang peroleh adalah siswa cenderung

Tabel 1. Jadwal Kegiatan Bimbingan Belajar

\begin{tabular}{|c|c|c|}
\hline No & Hari/Tanggal & Materi \\
\hline 1. & Selasa/3 Agustus 2021 & Operasi penjumlahan bilangan bulat dan pecahan \\
\hline 2. & Kamis/5 Agustus 2021 & Operasi penguragan bilangan bulat dan pecahan \\
\hline 3. & Sabtu/7 Agustus 2021 & $\begin{array}{l}\text { Operasi gabungan penjumlahan dan pengurangan bilangan bulat dan } \\
\text { pecahan }\end{array}$ \\
\hline 4. & Selasa/10 Agustus 2021 & Operasi perkalian bilangan bulat dan pecahan \\
\hline 5. & Kamis/12 Agustus 2021 & $\begin{array}{l}\text { Operasi gabungan penjumlahan dan perkalian bilangan bulat dan } \\
\text { pecahan }\end{array}$ \\
\hline 6. & Sabtu/14 Agustus 2021 & $\begin{array}{l}\text { Operasi gabungan pengurangan dan perkalian bilangan bulat dan } \\
\text { pecahan }\end{array}$ \\
\hline 7. & Selasa/17 Agustus 2021 & $\begin{array}{l}\text { Operasi gabungan pengurangan, penjumlahan dan perkalian } \\
\text { bilangan bulat dan pecahan }\end{array}$ \\
\hline 8. & Kamis/19 Agustus 2021 & Operasi pembagian bilangan bulat dan pecahan \\
\hline 9. & Sabtu/21 Agustus 2021 & $\begin{array}{l}\text { Operasi gabungan perkalian dan pembagian bilangan bulat dan } \\
\text { pecahan }\end{array}$ \\
\hline 10. & Selasa/24 Agustus 2021 & $\begin{array}{l}\text { Operasi gabungan penjumlahan dan pengurangan serta pembagian } \\
\text { bilangan bulat dan pecahan }\end{array}$ \\
\hline 11. & Kamis/26Agustus 2021 & $\begin{array}{l}\text { Memperdalam operasi perkalian dan pemgian bilangan bulat dan } \\
\text { pecahan }\end{array}$ \\
\hline 12. & Sabtu/28 Agustus 2021 & $\begin{array}{l}\text { Pembahasan operasi penjumlahan, pengurangan, perkalian dan } \\
\text { pembagian bilangan bulat dan pecahan. }\end{array}$ \\
\hline
\end{tabular}

Berdasarkan jadwal di atas, peserta pengabdian dibekali pengetahuan tentang operasi bilangan bulat multi digit dan pecahan. Pemberian materi diawali dengan penyampaian konsep sesuai dengan materi yang telah disusun, kemudian di lanjutkan dengan pemberian contoh-contoh sederhana 
sampai yang sulit (Setiawan \& Sumarah, 2019). Selama kegiatan berlangsung siswa sangat antusias dan menyenangi kegiatan ini, sehingga berdasarkan hasil tes akhir yang diberikan siswa mampu menyelesaikan permasalahan operasi bilangan bulat dan pecahan dengan nilai rata-rata 80 , serta mampu menyelesaikan tugas-tugas yang diberikan oleh guru disekolah.

Pada kegiatan LCC siswa dibagi dalam kedalam 5 kelompok kecil dengan tingkat pengetahuan serta kelas yang berimbang. Soal-soal disiapkan berdasarkan materi yang selama ini diajarkan pada kegiatan bimbingan dan diselingi dengan kasus yang berbentuk soal cerita. Siswa menyukai kegiatan ini dimana mereka antusias dan mau bersaing untuk menjawab soal yang diberikan. Pada kegiatan ini juga siswa diberi hadiah kejuaraan agar mereka semakin termotivasi dan menyukai matematika.

Pada tahap akhir kegiatan yang dilakukan adalah melakukan evaluasi akan kegiatan bimbingan yang dilakukan. Dari hasil angket yang diberikan kepada siswa $8 \%$ siswa sangat senang, $90 \%$ senang dan $2 \%$ netral dengan kegiatan bimbingan belajar ini. Disamping itu, agar kegiatan bimbingan ini tetap berjalan maka dibentuklah gugus bimbingan belajar yang dibawahi langsung oleh kepala desa.

Kegiatan bimbingan belajar dan LCC yang dilakukan di desa Simandraolo memiliki beberapa faktor pendukung dan penghambat. Faktor pendukung terlaksananya kegiatan pengabdian ini adalah:

1. Siswa sangat senang (Sujiwo, 2017) kegiatan bimbingan belajar dan LCC ini dilakukan. Hal ini dapat dilihat dari keaktifan siswa pada kegiatan ini.

2. Siswa terbuka akan kelemahan mereka pada pelajaran matematika sehingga memudahkan tutor untuk memberi solusi penyelesaian.

3. Orang tua sangat mendukung kegiatan ini dilakukan, buktinya mereka menghimbau anak-anak mereka untuk mengikuti bimbingan belajar dan LCC. Terlebih lagi pimpinan desa memberikan bantuan berupa hadiah kejuaraan pada kegiatan LCC.

Sedangkan faktor penghambat kegiatan bimbingan belajar dan LCC ini adalah:

1. Pada kegiatan bimbingan belajar matematika siswa lebih mengutamakan menggunakan bahasa daerah (Bahasa ibu) dalam menyampaikan pendapat. Sehingga siswa sedikit terkendala jika tutornya mengarahkan atau menginginkan menggunakan bahasa Indonesia. Untuk mengatasi permasalahan ini, siswa dihimbau untuk membiasakan menggunakan bahasa Indonesia dalam menyampaikan sesuatu secara khusus disaat berkomunikasi dengan teman. Jika terdapat kata yang sulit untuk diucapkan dengan baik disarankan untuk mengulangi mengucapkan kata tersebut berkali-kali.

2. Siswa yang memiliki tingkatan kelas lebih tinggi lebih mendominasi proses diskusi disetiap proses bimbingan belajar. Karena kegiatan ini dilakukan dengan tidak membagi menurut kelas, hal ini dilakukan karena keterbatasan waktu dan tempat. Dari permasalahan tersebut siswa yang tingkatan kelas paling rendah lebih diutamakan untuk menyampaikan pendapat.

\section{PENUTUP}

\section{Simpulan}

Berdasarkan kegiatan bimbingan belajar dan LCC yang dilakukan di desa Simandraolo dapat disimpulkan bahwa siswa kesulitan dalam melakukan operasi bilangan bulat dan pecahan. Secara khusus pada gabungan operasi bilangan, opersi pada bilangan bulat multi digit dan operasi pada bilangan pecahan. Kesulitan tersebut di atas dapat teratasi dengan melakukan bimbingan belajar dengan materi bilangan bulat dan pecahan serta melakukan kegiatan LCC agar siswa lebih termotivasi untuk belajar dan memiliki rasa percaya diri yang tinggi.

\section{Saran}

Berdasarkan kegiatan bimbingan belajar dan LCC yang dilakukan maka disarankan kepada siswan agar lebih giat lagi untuk belajar. Melakukan latihan yang sifatnya terus menerus dan berulang ulang sehingga konsep operasi bilangan bulat dan pecahan dapat tertanam dalam benak secara permanen. Serta membiasakan diri berkata-kata dengan berbahasa Indonesia dengan baik.

\section{E. DAFTAR PUSTAKA}

Ahmad, Habib Ratu Perwira Negara, Kurniawati, K. R. A., \& Santosa, F. H. (2019). Meningkatkan Motivasi Dan Prestasi Belajar Matematika Siswa Melalui Kegitan Bimbingan Belajar. JPMB : Jurnal Pemberdayaan Masyarakat Berkarakter, 2(2), 189-198.

https://doi.org/10.36765/jpmb.v2i2.14

Akbar, R. O., \& Cuyatno. (2016). PENGARUH MOTIVASI BIMBINGAN BELAJAR MATEMATIKA TERHADAP PRESTASI BELAJAR MATEMATIKA SISWA PADA POKOK BAHASAN PROGRAM LINIER. Eduma: Mathematics Education Learning and Teaching, 1(1), 14-29. https://doi.org/10.24235/eduma.v1i1.275 
Andriyani, M., \& Pranata, O. H. (2021). Faktor Penyebab Kesulitan Belajar Operasi Hitung Pembagian Bilangan Cacah pada Siswa Kelas V SD. PEDADIDAKTIKA : JURNAL ILMIAH PENDIDIKAN GURU SEKOLAH DASAR, $8(2), 292-300$.

Arsisari, A., Yopa, Karennisa, F., Farisma, S., Pendi, Juwita, I., Anis, F., \& 1, 2, 3, 4, 5, 6, 7*. (2021). Analisis Efektifitas Pembelajaran Matematika Secara Daring Siswa SMP di Kabupaten Bekasi Selama Masa Pandemi Covid-19. EMTEKA: Jurnal Pendidikan Matematika, 2(1), 73-80. https://doi.org/10.31004/cendekia.v5i3.875

Chairulhaq, A. I., Hendarti, A. M., Fendi, R. M., \& Fitrianto, A. R. (2021). PENDAMPINGAN BELAJAR DARING UNTUK MENGURANGI KECANDUAN GADGET PADA SISWA SEKOLAH DASAR. Edumaspul, 5(2), 63-74.

Dewi, K., Zayyun, L., Nisa, K., \& Susilawati. (2021). Peran Ekstrakurikuler Dalam Meningkatkan Prestasi Siswa Di SDN 3 Klangenan. Prosiding Dan Web Seminar (Webinar) "Standarisasi Pendidikan Sekolah Dasar Menuju Era Human Society 5.0," 498-505.

Fitriyani, Y., Fauzi, I., \& Sari, M. Z. (2020). Motivasi Belajar Mahasiswa Pada Pembelajaran Daring Selama Pandemik Covid-19. Jurnal Kependidikan: Jurnal Hasil Penelitian Dan Kajian Kepustakaan Di Bidang Pendidikan, Pengajaran Dan Pembelajaran, 6(2), 165-175.

Gularso, D., Suryantari, H., Rigianti, H. A., \& Martono. (2021). Dampak Pembelajaran Daring Terhadap Kemampuan Anak Usia Sekolah Dasar. Jurnal Pendidikan Dasar Nusantara, 7(1), 100-118. https://doi.org/10.29407/jpdn.v7i1.15890

Ilyas, S. A., Wahab, M. Y., \& Saleh, S. F. (2020). PENGARUH BIMBINGAN BELAJAR TERHADAP KESULITAN BELAJAR MATEMATIKA PADA MURID KELAS IV SD INPRES BERTINGKAT BUTUNG KECAMATAN WAJO KOTA MAKASSAR. SIGMA (Suara Intelektual Gaya Matematika), 12(1), 60-70.

Jera, R. P., Wuri, J. U., Koro, A. D., Umaratu, S. J., Bili, F. K., Radjah, J. C., Wibe, C. L., Mbaha, J. S. J., Kahendu, A., Roboth, E. M. L., Nicholas, N., Wehelmina, M., Nora, V. R., Mburu, Y. V. R., Ngadang, N. K., Amah, A. H. ., \& Lado, A. L. (2020). Pendampingan
Les Tambahan Mata Pelajaran Matematika di Taman Baca Gracia melalui Bimbingan Belajar Peserta Didik di Kelurahan Prailiu. Jurnal Pengabdian Barelang, 2(03), 1-4. https://doi.org/10.33884/jpb.v2i03.1969

Manik, S. (2020). Upaya Meningkatkan Layanan Bimbingan Belajar Untuk Meningkatkan Aktivitas Belajar Peserta Didik. Jurnal Pena Edukasi, 7(1), 29-34. http:/jurnal.goretanpena.com/index.php/JPE/ article/view/455

Nugraha, S. A., Sudiatmi, T., \& Suswandari, M. (2020). Studi Pengaruh Daring Learning Terhadap Hasil Belajar Matematika Kelas Iv. Jurnal Inovasi Penelitian, 1(3), 265-276. https://doi.org/10.47492/jip.v1i3.74

Rosidah, A., \& Faizal, N. (2020). BIMBINGAN BELAJAR TEKNIK PROBLEM SOLVING UNTUK MENINGKATKAN PENGELOLAAN DIRI DALAM BELAJAR. Jurnal Fokus Konseling, 6(1), 54-59.

Santoso, S., Negara, I. H. P., Damayanti, N. K. L. P., Putri, Y. R., Purnomo, O. R., \& Gago, M. S. (2021). KEGIATAN "FESTIVAL ANAK NEGERI" SEBAGAI WADAH PENGEMBANGAN BAKAT SISWA DI TENGAH PANDEMI COVID-19. DE JOURNAL (Dharmas Education Journal), 2(2), 287-294.

Saragih, E. M., Harahap, D. A., \& Ginting, D. (2020). Membangun Karakter Dan Potensi Diri Melalui Cerdas Cermat. Jurnal Anadara Pengabdian Kepada Masyarakat, 2(1), 50-54.

Sari, R. P., Tusyantari, N. B., \& Suswandari, M. (2021). Dampak Pembelajaran Daring Bagi Siswa Sekolah Dasar Selama Covid-19. Prima Magistra: Jurnal Ilmiah Kependidikan, 2(1), 9-15. https://doi.org/10.37478/jpm.v2i1.732

Sarlina. (2015). Miskonsepsi Siswa terhadap Pemahaman Konsep Matematika pada Pokok Bahasan Persamaan Kuadrat Siswa Kelas X5 SMA Negeri 11 Makassar. MaPan: Jurnal Matematika Dan Pembelajaran, 3(2), 194-209.

Sarumaha, R. (2018). Upaya meningkatkan kemampuan pemahaman konsep matematis siswa smas kampus telukdalam melalui model pembelajaran penemuan terbimbing. Jurnal Education and Development, 3(1), 68-72.

Sarumaha, R., \& Gee, E. (2021). IDENTIFIKASI 
HOMBO BATU SEBAGAI MEDIA PEMBELAJARAN DITINJAU SECARA MATEMATIS. AKSIOMA: Jurnal Program Studi Pendidikan Matematika, 10(1), 155-166. https://doi.org/10.1016/j.sciaf.2019.e00146

Setiawan, Y. B., \& Sumarah, I. E. (2019). Pendampingan Penerapan Bimbingan Pribadi Dan Bimbingan Belajar Matematika Untuk Membangun Resiliensi Siswa Kelas $6 \mathrm{Sd}$ Cahaya Bangsa Utama. Jurnal Berdaya Mandiri, 1(2), 110-121. https://doi.org/10.31316/jbm.v1i2.341

Simbolon, S., \& Harahap, A. (2021). Analisis Proses Pembelajaran Matematika pada Masa COVID-19. Jurnal Cendekia: Jurnal Pendidikan Matematika, 5(2), 2020-2028. https://doi.org/10.31004/cendekia.v5i2.646

Sujiwo, D. A. C. (2017). Bimbingan Belajar
Matematika Pada Siswa Sd Desa Kalidilem Lumajang. Jurnal Terapan Abdimas, 2, 41-47. https://doi.org/10.25273/jta.v2i0.975

Supriatna, I., Yuliawati, N., \& Firmansyah, W. (2017). Bimbingan belajar terhadap hasil belajar matematika. Tauhidi Jurnal PGSD, 4(1), 10-18.

Wondo, M. T. S., \& Meke, K. D. P. (2021) Analisis Pengaruh Sikap Percaya Diri Siswa Dalam Pembelajaran Matematika Menggunakan Model Pbl Berbantuan Bahan Manipulatif. Jupika: Jurnal Pendidikan Matematika, 4(1), 11-21. https://doi.org/10.37478/jupika.v4i1.894

Zulyanti, N. R. (2016). Persepsi Orang Tua Terhadap Lembaga Bimbingan Belajar Di Sakinah Edu Center Lamongan. Jurnal Penelitian Ilmu Manajemen, 1(2), 113-119. https://doi.org/10.30736/jpim.v1i2.26 